\title{
S.NET and NanoEthics: A Pair of Siblings
}

\author{
Christopher Coenen
}

Published online: 6 November 2015

(C) Springer Science+Business Media Dordrecht 2015

This editorial has been written on the way back from the 7th annual meeting of the Society for the Study of Nanoscience and Emerging Technologies (S.NET), which was once again a truly inspiring and instructive event. The conference was held in Montreal in October under the title "From Nanotechnologies to Emerging Technologies: Towards a Global Responsibility" and was mainly organised by the knowledge network Ne3LS, a very noteworthy long-term initiative set up by the Government of Quebec to examine the ethical, environmental, economic, legal and social issues raised by the development of nanotechnology.

S.NET and this journal can be described as a pair of siblings. NanoEthics is a little older, its first issue having been published back in 2007, while the first S.NET meeting annual meeting took place in 2009. Both are children of the first wave of research and discussions on nanotechnology, but also established themselves early on as important forums for reflection on new and emerging science and technology more generally, including other fields of technology and a wide variety of aspects of current technoscience. Recently, NanoEthics has changed its subtitle to Studies of New and Emerging Technologies, and S.NET is about to change its full name to the Society for Studies of New and Emerging

C. Coenen $(\bowtie)$

Institute of Technology Assessment and Systems Analysis (ITAS), Karlsruhe Institute of Technology (KIT), POB 3640,

76021 Karlsruhe, Germany

e-mail: christopher.coenen@kit.edu
Technologies. Both siblings are open to impulses that come from beyond academia, such as contributions by civil society activists, industry representatives, policy makers, early technology adopters and artists. There are large overlaps, not only thematically but also in terms of the people involved. While the journal's readers and contributors come from a wide variety of academic communities and NanoEthics is certainly not S.NET's house journal, there is clearly a special relationship between the two at many levels.

The present issue is a particular testament to this, since the authors of its first two articles gave talks in Montreal, and an entire special section is based on a session at last year's S.NET annual meeting.

In the first article, Vanessa Chenel, Patrick Boissy, Jean-Pierre Cloarec and Johane Patenaude analyse acceptability judgments concerning the use of nanocarrierbased targeted drug delivery. After sending out a questionnaire to a large number of Francophone scientists and scholars in Canada and Europe, they conducted interviews with a subset of the respondents, half of whom were French and half Canadian, while half were natural scientists or engineers and half social scientists or humanities scholars. The authors highlight contextual factors that bring about variability in acceptability judgments, arguing that effective consideration of these contextual factors could add a supplementary layer of information to assessment procedures and improve stakeholder discourse on technological innovation.

In the second article, Daniele Ruggiu contrasts two versions of Responsible Research and Innovation (RRI), the important new European approach to science, 
technology and innovation governance. From his point of view, it is possible to distinguish between a socioempirical version that tends to emphasise the role of democratic processes aimed at identifying values on which governance needs to be anchored, and a normative version that deems specific goals and fundamental rights declared by the European Union to be the best anchor points for both governance strategies and policy making. Ruggiu finds both versions unsatisfactory and argues for better integration of the parallel systems of human rights and European fundamental rights. Greater integration of these two systems could strengthen the anticipative features of RRI by allowing fundamental rights to function in a truly proactive fashion, with human rights issues being integrated into all phases of governance from the outset.

The present issue also features a special section on science and decision-making about emerging technologies that has been guest-edited by Christian Büscher and Jutta Jahnel, and was inspired by discussions at the 6th annual S.NET meeting held in Karlsruhe in September 2014. As regards the contents of these discussions and the articles in this special section - which have been written by the guest editors, Steffen Foss Hansen and Anders Baun, and Christopher Groves -, the reader is referred to the guest editors' introduction to the special section and, of course, the articles themselves. As far as this fine special section is concerned, I would merely like to point out that, coincidentally, the paper by Groves, which sets out a critique of an older article by Ruggiu [1], is now being published in the same issue as Ruggiu's new paper. Among other things, Groves criticises Ruggiu and René von Schomberg's [2] understanding of the role of rights in the RRI context. From Groves's perspective, human rights frameworks, whether international or not, are inadequate guides to the challenges posed by new and emerging science and technology. This discussion about the role of rights in RRI deserves to be continued, and I would like to invite not only Groves and Ruggiu to respond to each other's new articles, but also everyone working in the field to join in this conversation, which seems to me to be crucial for the study and governance of new and emerging technologies.

Although the present issue has been strongly shaped by the S.NET community and long-standing contributors to NanoEthics, we have, as always, also been joined by new authors: Beate Ochsner, Markus Spöhrer and Robert Stock have contributed a most remarkable analysis of the use and representation of cochlear implants in socio-technological environments. They discuss the cochlear implant as a boundary object that oscillates between an instrument used to enforce normalised technological hearing and a potential site for enabling transhuman ways of listening. Moreover, their article can be read very profitably in conjunction with the special section in NanoEthics 8(3) on self-made cyborgs and visions of transhuman corporeality and, in particular, Enno Park's discussion note in the same issue [3]. Last but not least, the present issue again - and, thanks to the efforts of our Book Review Editor Laura Cabrera, as usual - includes a book review, this time of Ethics and Emerging Technologies (2014), a volume edited by Ronald L. Sandler.

It only remains for me to wish you instructive, inspiring and enjoyable reading, a wonderful festive season and all the best for 2016 !

\section{References}

1. Ruggiu D (2013) Temporal perspectives of the nanotechnological challenge to regulation: how human rights can contribute to the present and future of nanotechnologies. NanoEthics 7(3):201-215

2. Von Schomberg R (ed) (2011) Towards responsible research and innovation in the information and communication technologies and security technologies fields, research and innovation policy. European Commission, Brussels

3. Park E (2014) Ethical issues in cyborg technology: diversity and inclusion. NanoEthics 8(3):303-306 